\title{
LIBERALISMO SIN LIBERTAD: UNIDAD RELIGIOSA Y ORDEN PÚBLICO EN LAS CONSTITUCIONES ESPAÑOLAS DE 1812 Y 1837
}

\section{LIBERALISM WITHOUT LIBERTY: RELIGIOUS UNITY AND PUBLIC ORDER IN 1812 AND 1837 SPANISH CONSTITUTIONS}

\author{
Alberto Cañas de Pablos* \\ Universidad Complutense de Madrid
}

SUMARIO: I. INTRODUCCIÓN.- II. CONSTITUCIÓN DE CÁDIZ. 1. Introducción. 2. Preámbulo Católico. 3. Regulación del hecho religioso y su discusión. 4. La religión más allá del artículo 12: sacralización política. 5. Abolición de la Inquisición.- III. CONSTITUCIÓN DE 1837. 1. Introducción. 2. Preámbulo y título I: los derechos. 3. Elementos dogmáticos del artículo 11. 4. Elementos económicos y de control sobre la Iglesia en el artículo 11. 5. Promulgación religiosa y años posteriores.- IV. CONCLUSIONES.

Resumen: Las dos primeras constituciones españolas (1812 y 1837) debieron enfrentarse a la cuestión de la religión como hecho político y social. Durante su elaboración, los parlamentarios tuvieron que decidir cómo sería la legislación relativa a ese punto tan polémico. Las restricciones sobre la libertad religiosa a menudo chocaban con la proclamación de la defensa de las libertades en otros ámbitos. De nuevo la necesidad de orden exigía limitar las libertades relacionadas con la fe.

Abstract: The first two Spanish Constitutions (1812 and 1837) had to face the matter of religion as a political and social fact. During their drawing up, deputies had to decide how the new legislation of that polemical topic would be. Restrictions on religious liberty often crashed with words defending liberties in other aspects. One more time, the necessity of public order demanded the limitations of liberties related to faith.

Palabras clave: Liberalismo, Constitución 1812, Constitución 1837, Libertad religiosa, Relaciones Iglesia-Estado

Keywords: Liberalism, 1812 Constitution, 1837 Constitution, Religious freedom, Church-State relationships

Artículo presentado con el apoyo del Programa de Financiación de la Universidad Complutense de Madrid-Santander Universidades, Convocatoria 2014 (CT4-14). 
Los españoles han de ser libres, en todo menos en sus conciencias. José María Blanco White ${ }^{1}$ España será liberal en todo, menos en religión.

Diego Muñoz Torrero²

\section{I.-INTRODUCCIÓN}

En cada sociedad lo espiritual y sus expresiones prácticas han contado con gran arraigo, por lo que cualquier regulación sobre ello ha tenido gran repercusión política y social. Como consecuencia, esta normativa ha sufrido menos cambios o, si los ha habido, han sido menos radicales que en otros campos. $^{3}$

Este fenómeno se hace más profundo en el caso español. La causa principal es el tradicional vínculo entre religión católica e identidad nacional. La catolicidad de España quedó siempre fuera de toda duda, y lo que se discutió fueron puntos como la (in)tolerancia religiosa o la ciudadanía católica. ${ }^{4}$ La llamada "cuestión religiosa" ha surgido en muchas ocasiones en la evolución del constitucionalismo español, así como en la dinámica política del país.

Durante los enconados debates, miembros de las Cámaras con diferente procedencia ideológica coincidieron en defender el papel cohesionador de la unidad de culto para la gobernabilidad. En la etapa liberal los politicos españoles desarrollaron líneas de articulación politica de corte confesional, ${ }^{5}$ es decir, hubo avances, pero siempre lejanos a toda laicidad; parecía que cualquier exceso podría destruir la fragilísima estabilidad conseguida. Más allá de la pluralidad religiosa, insignificante en España, uno de los problemas más espinosos de la consolidación del estado liberal fue el rol político y social que debía jugar la Iglesia Católica; su reconversión no fue fácil.

Para este artículo se han seleccionado las constituciones de 1812 y 1837. ¿Por qué estos textos? Ambos se enmarcan en la primera fase del anticlericalismo español en el siglo XIX. Esta etapa inicial, inmersa en la crisis del Antiguo Régimen, se caracterizó por un programa amplio de reformas, cuyos puntos principales fueron la supresión de la Inquisición, la modificación del sistema económico de la Iglesia a través de medidas desamortizadoras, así como la

1 José Blanco White, Cartas de Juan Sintierra (Crítica de las Cortes de Cádiz), Sevilla, Universidad de Sevilla, 1990 [1811], pp. 141-142, mencionado en Gregorio Alonso García, La nación en capilla: ciudadanía católica y cuestión religiosa en España, 1793-1874, Granada, Comares, 2014, p. 49. Así criticaba de forma irónica el artículo gaditano que declaraba la catolicidad de España.

2 Citado en Manuel Suárez Cortina, Entre cirios y garrotes: politica y religión en la España contemporánea. (1808-1936), Cuenca y Santander, Universidades de Castilla-La Mancha y de Cantabria, 2014, p. 38.

3 Isidoro Martín Sánchez, "Prólogo" en Ricardo García García, Constitucionalismo español y legislación sobre el factor religioso durante la primera mitad del siglo XIX (1808-1845), Valencia, UAM-Tirant lo Blanch, 2000, p. 19.

4 Manuel Suárez Cortina, Entre cirios y garrotes: politica y religión en la España contemporánea. (1808-1936), op. cit., p. 36.

5 Gregorio Alonso García, "Ciudadanía católica y ciudadanía laica en la experiencia liberal", en Manuel Pérez Ledesma (dir.), De súbditos a ciudadanos. Una historia de la ciudadanía en España, Madrid, CEPC, 2007, p. 172. 
reducción del número de efectivos del clero. A ello se unían los intentos para lograr el incremento del control estatal sobre la Iglesia, desligándola lo máximo posible de Roma. ${ }^{6}$

Además, los dos textos aparecieron en momentos de incertidumbre politica y social en España: la invasión napoleónica y la ausencia de monarca, y la primera guerra carlista, respectivamente, mediatizaron profundamente su redacción. La primera inició el constitucionalismo español (dejando a un lado el Estatuto de Bayona, cuyas particularidades impiden considerarlo una constitución), mientras que la segunda fue la única del siglo que tuvo como base un auténtico consenso entre moderados y progresistas.

\section{II.-CONSTITUCIÓN DE CÁDIZ}

\section{1.-Introducción}

La Constitución de 1812 fue un texto netamente liberal, excepto en el aspecto religioso: proclamó una fuerte catolicidad de la nación. La católica era la religión oficial, y además prohibió el ejercicio de cualquier otra. Se unía de ese modo a una forma de pensamiento dominante en nuestro país desde el siglo XVI que asumía la asociación entre la tradición católica y el carácter de España ${ }^{7}$ y que aún permanecería viva durante unas cuantas décadas, especialmente entre ciertos sectores políticos y sociales conservadores.

Las Cortes de Cádiz comenzaron una etapa en la que se sucederían elementos aparentemente contradictorios como la declaración de confesionalidad de 1812 y la eliminación de la Inquisición y los diezmos junto a intentos de reforma de la Iglesia. Todo ello en una asamblea en la que tres de cada diez miembros eran eclesiásticos, 8 lo que los convertía en el grupo más numeroso entre los parlamentarios. Aun así, conviene tener en cuenta que tenían rangos diferentes, ya que habia desde párrocos rurales hasta obispos, y defendian posturas diversas.

\section{2.-Preámbulo Católico}

El cariz que iban a tomar las Cortes gaditanas en cuanto a aspectos religiosos se observa ya en el Preámbulo constitucional. Dicha parte del texto proclamaba la Constitución "En el nombre de Dios todopoderoso, Padre, Hijo y Espíritu Santo autor y supremo legislador de la sociedad”, o lo que es lo mismo,

6 Manuel Revuelta González, "El anticlericalismo español en el siglo XIX", en Paul Aubert (ed.): Religión y sociedad en España: (siglos XIX y XX): seminario celebrado en la Casa de Velázquez (1994-1995). Madrid, Casa de Velázquez, 2002, pp. 161-162.

7 Manuel Suárez Cortina, Entre cirios y garrotes: politica y religión en la España contemporánea. (1808-1936), op. cit., p. 38. y Emilio La Parra López: “Iglesia Católica", en Javier Fernández Sebastián y Juan Francisco Fuentes (dirs.), Diccionario político y social del siglo XIX español, Madrid, Alianza Editorial, 2002, p. 355.

8 Francisco Martí Gilabert, La abolición de la Inquisición en España, Pamplona, Universidad de Navarra, 1975, pp. 60-61. Las cifras varian entre 90 y 100 diputados sobre un total (variable) de 300. 
realizaba toda una profesión de fe. Respecto a la propuesta inicial hubo pareceres distintos en cuanto a su posible reforma. Los "serviles" propusieron acentuar más aún el carácter religioso de esta parte del texto constitucional, llegando a sugerir la inclusión de la Virgen en el párrafo, mientras que los liberales estaban satisfechos con el texto que había sido presentado por la Comisión, ${ }^{9}$ que finalmente se aprobó sin alteraciones.

\section{3.-Regulación del hecho religioso y su discusión}

Su artículo 12 es el dedicado a la cuestión religiosa ("La religión de la Nación española es y será perpetuamente la católica, apostólica, romana, única verdadera. La Nación la protege por leyes sabias y justas y prohíbe el ejercicio de cualquier otra") y refleja el triunfo de las posturas más conservadoras. No es de la religión del individuo de lo que habla, sino de la creencia oficial, exclusiva y excluyente, de la Nación entendida como sujeto uniforme. Esta declaración taxativa de la confesionalidad católica de la Nación implica una obligación perpetua. El texto incluye dos elementos importantes: la protección legislativa posterior de la religión católica y la prohibición de otras confesiones. ${ }^{10}$

Que España fuese una de las cunas del liberalismo era compatible con la intolerancia religiosa. ${ }^{11}$ De hecho, hubiera sido absurdo implantar la libertad religiosa completa mientras la Inquisición aún funcionaba. Con la consagración de dicha intolerancia, la condición de católico constituía el pilar básico de la ciudadanía: así nace la "ciudadanía católica". Teniendo en cuenta el preámbulo y el artículo mencionado, no puede decirse, como tantas veces se ha afirmado, que dichas Cortes eran anticlericales o enemigas de la Iglesia.

Las alternativas venían desde todas las posturas. Los diputados absolutistas buscaron endurecer su contenido incluyendo la obligatoriedad de profesar la fe católica, pero Flórez Estrada y Blanco White (éste último desde Inglaterra), siguiendo sus convicciones liberales, sugirieron introducir elementos de libertad de conciencia. Para ellos, no convenía la coacción al imponer las creencias, ya que nacerian enemistades con países no católicos. Propuestas como las suyas fueron rechazadas rotundamente, y así seguiria siendo, no sin algunos matices, hasta 1869. No hay que olvidar el elevado número de eclesiásticos presentes en las Cortes gaditanas, que presionaron a favor de las máximas restricciones posibles.

Al no cederse a las pretensiones más extremistas de todo signo, se creían evitados problemas serios en el futuro. A pesar de ello, el tratamiento gaditano de la cuestión religiosa es una excepción al espíritu liberal del resto de la

\footnotetext{
${ }^{9}$ Emilio La Parra López, El primer liberalismo español y la Iglesia. Las Cortes de Cádiz, Alicante, Instituto de Estudios Juan Gil Albert, 1985, p. 37.

10 Manuel Revuelta González, "La confesionalidad del Estado en España”, en Emilio La Parra y Jesús Pradells (eds.), Iglesia, sociedad y Estado en España, Francia e Italia (ss. XVIII al XX), Alicante, Instituto de Cultura Juan Gil-Albert, 1992, p. 377.

11 Manuel Suárez Cortina, Entre cirios y garrotes: politica y religión en la España contemporánea. (1808-1936), op. cit., p. 38.
} 
Constitución de $1812,{ }^{12}$ plasmado en el reconocimiento de la soberanía nacional y la división de poderes. En el entramado constitucional se sitúa fuera del apartado de los derechos, a iniciativa de los liberales avanzados. Se buscaba evitar que la religión pudiera ser considerada como un derecho, y al mismo tiempo no podía aparecer como una tendencia a abrir la puerta a la tolerancia religiosa. Además, algunos de los diputados más conservadores se oponían a la constitucionalización de la religión, porque de ese modo quedaba sometida al Estado, una intromisión intolerable para ellos. Aun así, según la forma final del texto constitucional, todo ataque a la religión era implícitamente una agresión a la ley y al Estado, y la legislación de los años posteriores (incluyendo la del Trienio Liberal) seguirá dicha vía, llegando a recoger incluso penas de muerte ${ }^{13}$ para quienes intentasen establecer en España una religión alternativa a la católica.

El planteamiento inicial de la Comisión decía lo siguiente: "La Nación española profesa la religión católica, apostólica, romana, única verdadera, con exclusión de cualquier otra". El eclesiástico Pedro Inguanzo fue el primero en responder a dicha propuesta de la Comisión. Calificó de tibio al texto porque sólo reconocía algo obvio: el catolicismo de España. Pone énfasis en la importancia de la religión, indispensable en la condición de españolidad y como herramienta de la obediencia legal:

\begin{abstract}
La religión debe entrar en la Constitución como una ley que obligue á todos los españoles á profesarla, de modo que ninguno pueda ser tenido por tal sin esta circunstancia. La religión es la primera de todas las leyes fundamentales, porque todas las demás estriban en ella; y sin ella, y sin los preceptos que por ella comunica su divino autor, no tienen fuerza ni obediencia las leyes humanas, y todo el edificio de la sociedad viene por tierra. ${ }^{14}$
\end{abstract}

La religión obligatoria es primordial para la obediencia hacia las leyes y para ser considerado como español. O lo que es igual, supone un pilar indispensable para el orden público. Al día siguiente, Muñoz Torrero y Villanueva presentaron una segunda versión del artículo, más completa y restrictiva, que fue la finalmente aprobada el mismo 3 de septiembre de 1811.

\title{
2.4.-La religión más allá del artículo 12: sacralización política
}

No sería la única cuestión relacionada con el clero que tratarian las Cortes de Cádiz. Su largo y detallado articulado está impregnado de elementos religiosos, alentados por el temor a que se produjese un cisma, y siempre de acuerdo con lo

12 Manuel Segura Ortega, “Los derechos fundamentales en la Constitución de Cádiz de 1812" en Francisco Puy Muñoz (coord.), Los derechos en el constitucionalismo español, Santiago de Compostela, Universidade de Santiago de Compostela, 2002, p. 27.

13 Manuel Suárez Cortina, Entre cirios y garrotes: politica y religión en la España contemporánea. (1808-1936), op. cit., p. 42.

14 Diario de Sesiones de las Cortes Generales y Extraordinarias, $\mathrm{n}^{\circ} 335,2$ de septiembre de 1811 , p. 1745 . 
establecido en el Concordato de 1753. Incluye rituales de sacralización política, 15 como la elección de lugares pertenecientes a la Iglesia para la celebración de elecciones (art. 34), la misa previa con un discurso del párroco sobre las "circunstancias" (art. 47) y el Te Deum tras la jornada electoral (art. 58). E1 artículo 117 recoge el juramento que debían hacer los votados como electores:

\begin{abstract}
En todos los años, el día 25 de Febrero, se celebrará la última junta preparatoria, en la que se hará por todos los Diputados, poniendo la mano sobre los Santos Evangelios, el juramento siguiente: ¿Juráis defender y conservar la religión Católica, Apostólica, Romana, sin admitir otra alguna en el Reino? -R. Sí juro. -¿Juráis guardar y hacer guardar religiosamente la Constitución política de la Monarquía española, sancionada por las Cortes generales y extraordinarias de la Nación en el año de 1812? -R. Sí juro. ¿Juráis haberos bien y fielmente en el cargo que la Nación os ha encomendado, mirando en todo por el bien y prosperidad de la misma Nación? -R. Sí juro. -Si así lo hiciereis, Dios os lo premie, y si no, os lo demande.
\end{abstract}

Este juramento, celebrado en parroquias o catedrales y con la mano sobre la Biblia, está compuesto por tres preguntas, ordenadas jerárquicamente. Antepuesto al juramento de fidelidad a la Constitución, aparece la defensa de la religión católica sin permitir ninguna otra en España, obligatoriedad que aparece tanto en el juramento real como en el del Príncipe de Asturias. Se reserva para el final el juramento sobre un desempeño justo y desinteresado del cargo. El juramento como monarca añadía la prohibición de enajenar partes del reino, junto a la obligación de respetar la libertad nacional (art. 173), entre otros elementos.

La confesionalidad de la Constitución de Cádiz era absoluta, sin que ningún texto en el occidente europeo tuviera una declaración religiosa tan contundente. Sin embargo, no sería obstáculo para que en los meses siguientes surgiese el debate sobre la compatibilidad entre la Inquisición y la "Pepa".

En otro orden de cosas, el Decreto aprobado el 17 de junio de 1812 recogía el secuestro de todos los bienes pertenecientes á establecimientos públicos, Cuerpos consulares y eclesiásticos extinguidos, etc. Además, se prohibió el restablecimiento y mantenimiento de los conventos que no alcanzasen los doce individuos, ${ }^{16}$ lo que supuso la primera cercenación del siglo en ese sentido.

\title{
2.5.-Abolición de la Inquisición
}

Junto al reconocimiento de la religión católica como oficial-nacional y la sacralización de las prácticas políticas, las Cortes de Cádiz se ocuparon entre 1812 y 1813 de una tercera cuestión relacionada con la religión: la abolición de la Inquisición. La Comisión que preparó ese proyecto era consciente del potencial

15 Gregorio Alonso García, La nación en capilla: ciudadanía católica y cuestión religiosa en España, 1793-1874, op. cit., p. 43.

16 Jerónimo Bécker, Relaciones diplomáticas entre España y la Santa Sede en el siglo XIX, Madrid, Imp. de Jaime Ratés, 1908, p. 38. 
pacificador que suponía la unidad religiosa en España, como manifestaría en sus informes:

En todo tiempo las novedades de esta clase [diversidad de fe] han turbado la tranquilidad de los estados, acalorado los ánimos, excitado odios y disensiones, fomentado guerras civiles, y dado ocasión a que los facciosos hagan correr la sangre de los ciudadanos pacíficos y sencillos. (...)

El [medio] más poderoso de todos (...) sobre que descansa todo el órden social, es la religion, y particularísimamente la santa y divina de Jesucristo, fundada en los dos sublimes preceptos del amor de Dios y del prójimo, los cuales, no solo comprenden el más exacto cumplimiento de las obligaciones de los hombres para con sus iguales, sino las de los súbditos para con sus superiores, y las de estos para con los que los obedecen. ${ }^{17}$

Cumplimiento de la ley, orden social e influencia de la religión católica como única presente y permitida entre los españoles eran una constante. Por las características a él atribuidas, el credo católico, único posible, garantiza y apoya la pervivencia del orden público y la obediencia de la nación, frente a las disensiones religiosas que han provocado siempre graves desórdenes.

En el debate parlamentario sobre la Inquisición intervinieron los diputados de mayor entidad: Mejía Lequerica (diputado por Quito), Argüelles, el conde de Toreno, Inguanzo... ${ }^{18}$ Entre quienes se oponían a la pervivencia de la Inquisición destacó Antonio Puigblanch, ilustrado eclesiástico catalán que bajo el pseudónimo de Natanael Jomtob escribió La Inquisición sin máscara, donde acusaba al Santo Oficio de poner en peligro la "verdadera creencia" a causa de la dureza de sus procesos, la falta de mansedumbre cristiana y el fomento de la hipocresía. ${ }^{19}$

$\mathrm{Su}$ oposición a la Inquisición no incluyó la crítica al hecho religioso ni a cuestiones de fe. De hecho, atacaba al ateísmo tildándolo de egoísta que solo actúa en pos de su bienestar individual. Defendía la necesidad de un ente superior unificado que cumplía la función de garante del orden social a través de la confianza mutua que producia el hecho de compartir creencias.

No ha existido jamás, ni es posible que exista, reunión alguna de hombres en sociedad, que merezca el nombre de tal sin que primero se establezca por base la creencia de la divinidad manifestada por un culto exterior, que asegurando la confianza recíproca de los ciudadanos, sea el agente poderoso que los

17 Discusión del proyecto de decreto sobre el tribunal de la Inquisición, sesiones del 8 de diciembre de 1812 y del 4 de enero de 1813, pp. 4190 y 4212.

18 Emilio La Parra y María Ángeles Casado, La Inquisición en España. Agonía y abolición, Madrid, Los libros de la Catarata, 2013, pp. 101-102.

19 Gregorio Alonso Garcia, La nación en capilla: ciudadanía católica y cuestión religiosa en España, 1793-1874, op. cit., p. 51. 
estimule incesantemente al cumplimiento de la ley, y el freno que contenga sus apetitos particulares dentro de los limites de la utilidad general.20

Para Puigblanch, las creencias religiosas compartidas constituian un instrumento indispensable para que se cumpliesen las leyes y fuese posible la convivencia. Por ello, la religión debía estar presente en la Constitución, y en un lugar preeminente, pero no debía confiarse su salvaguardia a un tribunal.

Para el afrancesado Juan Antonio Llorente la existencia y supervivencia de este tribunal se basó en el afán de sus miembros por llevar a cabo confiscaciones, por el fanatismo, la superstición, el despotismo o la ignorancia de los reyes. ${ }^{21}$ Aunque detractor del tribunal, se expresó a priori contradictoriamente y aduló su acción reconociendo su labor en el pasado:

\begin{abstract}
¿Se habla de política? ¡Feliz España (dicen) que con solo mantener el Santo tribunal estás libre de las convulsiones intestinas que con mucha frecuencia ponen a los otros reinos en peligro de perderse por la diversidad de religiones entre sus habitantes, y por la falta de un Santo Oficio que persiga, castigue y extermine los herejes! 22
\end{abstract}

La unidad religiosa pertenece a la razón de Estado, y el autor era consciente de que la Inquisición llevaba siglos trabajando para favorecerla, evitando problemas internos. Junto a la conservación del dogma se oponía a la heterogeneidad religiosa, constante foco de dificultades en otras sociedades.

Por norma, el clero se opuso a cualquier cambio en el estatus de la Inquisición, comenzando por negar que las Cortes poseyeran la potestad para regular cuestiones vinculadas al Tribunal, ya que lo vinculado con la religión correspondia a la autoridad eclesiástica. Si había habido tolerancia en el pasado medieval, ésta sólo se había mantenido mientras la situación no llevó a problemas vinculados al orden público, ${ }^{23}$ momento en el que se decidió por establecer la Inquisición y terminar con la diversidad religiosa.

No obstante, esta estrategia no fue ni mucho menos monolitica. Por ejemplo, el agustino moderado Lorenzo Frías, reflejaba la crispación entre los miembros

20 Natanael Jomtob, La Inquisición sin máscara, o disertación en que se prueban hasta la evidencia los vicios de este tribunal y la necesidad de que se suprima, Cádiz, Imp. José Nief, 1811, pp. 4-7.

21 Ana Isabel González Manso, "Tolerancia religiosa y modelo de Iglesia en España en la primera mitad del siglo XIX”, Historia Constitucional, n 15,2014 , p. 134.

22 Juan Antonio Llorente: Memoria histórica sobre qual ha sido la opinión nacional de España acerca del tribunal de la Inquisición, leida en la Real Academia de la Historia por el Excelentísimo señor Don Juan Antonio Llorente, consejero de Estado, dignidad de maestrescuelas y canónigo de Toledo, caballero comendador de la Orden real de España; comisario general apostólico de cruzada, Cádiz, Imp. de Sancha, 1812, p. 2.

23 Ana Isabel González Manso, "Tolerancia religiosa y modelo de Iglesia en España en la primera mitad del siglo XIX”, op.cit., p. 126. 
del clero, restando importancia a las proclamas agoreras lanzadas por quienes pronosticaban caos y apocalipsis si el Santo Oficio desaparecia: ${ }^{24}$

¡Qué levantar el grito sobre que todo va perdido! La Inquisición se quita, la religión se trastorna y la patria se aniquila. Oyen estos clamores las gentes, y como no tienen obligación ni luces para discernir, piensan que lo que oyen a los eclesiásticos es el Evangelio (...), he aquí sembrado inconsideradamente un principio de división, de cisma y de guerra civil, de que Dios nos libre (...) siempre que he oído hablar en tono, no digo de desear, sino de no temer un alboroto de los pueblos o división de partido, me estremezco.

Los liberales basaron su defensa de la abolición de la Inquisición en la incompatibilidad de dicha institución con la nueva Constitución, partiendo de sus tres principios: plena soberanía nacional, división de poderes y garantía de los derechos individuales. Las falsas conversiones de judios justificaron su creación en el pasado, pero la posterior arrogación de poderes traspasó muchos límites, deslegitimándose ${ }^{25}$ con el tiempo y con su propia actuación. Se la acusaba de ser la herramienta con la que el despotismo, el mayor mal de España para la mayoría de los liberales, se perpetuó. Además, la pervivencia del catolicismo en España quedaba garantizada por lo recogido en el precepto constitucional correspondiente (artículo 12), por lo que no habia nada que temer.

El fin de la Inquisición se aprobó por 80 votos favorables y 60 contrarios, lo que refleja la división existente en torno a esta cuestión. Resulta sorprendente teniendo presente la significativa caída de la actividad del tribunal en las últimas décadas, además de las constantes críticas procedentes del extranjero. A pesar de esta decisión parlamentaria, algunos eclesiásticos no leyeron en las iglesias el decreto de abolición, incumpliendo dicha obligación legal. Lo que no apareció en el proceso de abolición de la institución inquisitorial fueron debates sobre las verdades fundamentales del catolicismo, garantizadas desde la aprobación de la Constitución, ${ }^{26}$ y que nadie puso en duda. Una ruptura así era sencillamente inconcebible, a pesar de lo cual, el retorno a España de Fernando VII acarreó la vuelta a la vigencia de la Inquisición.

Pero la unidad de cultos no era lo único que facilitaba la estabilidad politica: controlar el clero era una herramienta importante. Nunca hubo intención de ceder los privilegios regalistas por los legisladores gaditanos, e incluso Fernando VII, a pesar de su postura más favorable hacia el clero, continuaria ejerciendo su derecho de presentación de aquellos obispos con cuya fidelidad política pudiese contar. El juego de equilibrios entre ambos poderes seguiría siendo continuo.

24 Leandro Higueruela del Pino, "La Iglesia y las Cortes de Cádiz", Cuadernos de Historia Contemporánea, $\mathrm{n}^{\mathrm{o}}$ 24, 2002, p. 75.

25 Emilio La Parra y María Ángeles Casado, La Inquisición en España. Agonía y abolición, op. cit., p. 104.

26 Ibid, p. 98. 


\section{III.-CONSTITUCIÓN DE 1837}

\section{1.-Introducción}

Tramitada inicialmente como reforma de la Carta de Cádiz, la Constitución de 1837 terminó teniendo entidad propia e introduciendo cambios significativos. El tratamiento de la cuestión religiosa fue una de las novedades más reveladoras. Conviene tener presente su carácter transaccional27, que amalgamó principios progresistas y moderados en aras de una estabilidad politica que nunca llegaria. Esa simbiosis marcará el carácter del texto, con la consecuencia de dar vaguedad a parte de sus contenidos.

Para muchos el texto aprobado en 1812 había resultado demasiado avanzado, mientras que el Estatuto Real (1834) solo era una tímida convocatoria electoral que en realidad suponía un retroceso. Se veía a la nueva Constitución como una transacción entre ambos y entre los dos proyectos liberales que se alternarian en el XIX. ${ }^{28}$ Las dos formaciones mayoritarias reconocieron que el texto era mejorable, pero también admitían que recogía la mayoría de sus aspiraciones centrales. Los progresistas (auténticos arquitectos de la Constitución) la habían redactado sacrificando algunos principios, como el unicameralismo; por su parte, los moderados la aceptaban dejando constancia de que no recogía todas sus aspiraciones, aunque los "materiales" con que se había construido procedian de su campo doctrinal.

\section{2.-Preámbulo y Título I: los derechos}

La Constitución de 1837 cuenta con un Preámbulo en el que, además de indicarse que técnicamente es una reforma de su antecesora de 1812, destaca la desaparición de la invocación religiosa, marcando una diferencia importante con el aprobado cuarto de siglo antes. La única referencia cristiana aparece cuando se indica que Isabel II es reina "por la gracia de Dios".

La carta comienza con una declaración de derechos en el Título I, llamado "De los españoles". En palabras de la Comisión que lo elaboró, pretendía reunir los artículos dispersos en el código gaditano y que "fijan los derechos políticos de los españoles y establecen en las garantías de su seguridad individual los limites que tendrán que respetar los diferentes poderes del Estado". ${ }^{29}$ Esta novedosa formulación plasmaba sistematizadamente los sucesivos derechos reconocidos por la constitución.

27 Joaquín Varela Suanzes-Carpegna, “La Constitución española de 1837: una Constitución transaccional”, Revista de Derecho Politico, n 20, 1983-1984, pp. 95-97.

28 Joaquín Tomás Villaroya, "La publicación de la Constitución de 1837”, Revista de Derecho Político, n 20, 1983-1984, p. 18 y Manuel Suárez Cortina, Entre cirios y garrotes: politica y religión en la España contemporánea. (1808-1936), op. cit., pp. 48-49.

29 Maria Cruz Romeo Mateo, “Lenguaje y política del nuevo liberalismo: 1834-1845", Ayer, no 29, 1998, pp. 57-58. 


\title{
3.3.-Elementos dogmáticos del artículo 11
}

El artículo undécimo, dedicado a la cuestión religiosa, cierra este Título I, quedando recogido por tanto dentro de los derechos. Muy breve, supone una ruptura notable ante la confesionalidad total de 1812: "La nación se obliga a mantener el culto y los ministros de la religión católica que profesan los españoles". Resuelta en menos de veinte palabras, de esta forma nacía la confesionalidad sociológica y desaparecía la visión teológica de la ciudadanía.

Por confesionalidad sociológica se entiende el reconocimiento por parte del Estado de que la gran mayoría de sus ciudadanos profesan la religión católica. ${ }^{30}$ Así, la Nación no tenía religión oficial, pero al tiempo se constataba que la religión católica era mayoritaria, pero no obligatoria ni excluyente.

¿Cómo se llegó a esta redacción? El origen está en la Exposición de la Comisión de las Cortes presentando el proyecto de Constitución, donde se justifica la propuesta del artículo tal y como sería aprobado finalmente: 31

\begin{abstract}
"El art. 12 de la nuestra [la "Pepa"] ha parecido a muchos ajeno de un Código político; y en verdad que lejos de añadir nada los hombres a lo sublime de la religión con la declaración que aquél contiene, más parece que rebajan su origen divino sujetándola a semejante confirmación; pero el omitir totalmente este artículo podría dar lugar a muy peligrosas interpretaciones; y aun prescindiendo de esta consideración, cuya importancia y trascendencia apreciarán las Cortes debidamente, cree la comisión que debe consignarse solamente el hecho de que los españoles profesamos la religión católica, y la obligación en que la Nación está de mantener a sus ministros y de atender a los gastos de su culto."
\end{abstract}

Es decir, la legislación de 1812 equiparaba algo tan trascendental como la religión con otros elementos más "mundanos" también regulados. Pero también reconocían la conveniencia de incluirlo para evitar conclusiones oscuras y restrictivas que llevasen a efectos indeseados. De ahí nace esa opción tímida, meramente declarativa y con un formato casi "de silencio", que permitía ser interpretada en sentidos opuestos. Aunque no se prohíbe ningún culto, tampoco se permite explícitamente el no católico. A eso se añade el componente económico de sostenimiento del clero, analizado más adelante.

Existía cierta tendencia no clerical (el adjetivo "anticlerical" quizá sea imprudente) en las Cortes, pero se consideró que la inclusión explícita de la libertad religiosa podía ser excesiva, creando discrepancias insalvables que quebrarian el consenso pretendido. Por ello, se apostó por una vía intermedia que ponía negro sobre blanco la preeminencia del catolicismo en España, pero que, sin tolerar otras religiones, sí hacía lo propio con aquellos individuos que no

30 Francisco José Zamora García, "Antecedentes constitucionales de la libertad religiosa", Anuario Jurídico y Económico Escurialense, nº XLV, 2012, p. 198.

31 Recogida por Francisco José Zamora Garcia, "Antecedentes constitucionales de la libertad religiosa", op. cit, p. 198n. 
profesasen dicha creencia. ${ }^{32}$ Aunque había diputados de todas las tendencias, en general, el ambiente era de cierto recelo hacia el clero como actor político. Resultado de ello es el artículo 23, que establecía la inelegibilidad de los eclesiásticos para convertirse en diputados.

Además, al contrario que en 1812, no había una invocación expresa a una religión nacional calificada como "única y verdadera", exclusiva y excluyente. Esto es, la Constitución de 1837 carece de una valoración del hecho religioso. Para los liberales progresistas de los años treinta el vínculo entre nación y religión era muy endeble, por lo que optaron por la inclusión implícita de la tolerancia religiosa (una fórmula negativa que no mencionaba métodos de exclusión religiosa). La rotunda posición establecida en su día por las Cortes gaditanas será considerada como un error por muchos liberales, que lamentaban la oportunidad perdida: "Una declaración puramente dogmática, propia de un Concilio", dirá en sede parlamentaria Joaquín María López. ${ }^{33}$ Destaca la profunda reflexión efectuada por Argüelles desde su exilio londinense en su Examen (1833), poco antes de regresar a España, posición en la que incidiría en sede parlamentaria durante los debates a la propuesta de Constitución de 1837:

En el punto de la religión se cometía [en 1812] un error grave, funesto, origen de grandes males, pero inevitable. Se consagraba de nuevo la intolerancia religiosa (...) Para establecer la doctrina contraria hubiera sido necesario luchar frente á frente con toda la violencia y furia teológica del clero (...) Por eso se creyó prudente dejar al tiempo, al progreso de las luces, á la ilustrada controversia de los escritores, á las reformas sucesivas y graduales de las Cortes venideras, que se corrigiese, sin lucha ni escándalo, el espíritu intolerante que predominaba en una gran parte del estado eclesiástico.

Los que se abstuvieron entonces hasta de contradecir los indiscretos términos de aquel artículo, lo hicieron en obsequio de la paz y harmonía (sic) que sinceramente deseaban conservar con un clero ingrato (...) que retribuyó esta generosa condescendencia, (...) con una persecución, inaudita y cruel contra los que le defendieron y honraron, y no menos ignominiosa y funesta para la nación á quien robó después toda la gloria y utilidad del triunfo que se había conseguido. ${ }^{34}$

Según sus palabras, la redacción confesional de "la Pepa" fue fruto del deseo de evitar enfrentamientos directos con el clero, que tenía capacidad suficiente para alterar el orden público y aun así, a su juicio, respondió durante las dos décadas siguientes con persecuciones y ataques contra quienes habian abogado

32 Joaquín Rodríguez-Toubes Muñiz, "Los derechos fundamentales en la Constitución española de 1837”, en Francisco Puy Muñoz (coord.), Los derechos en el constitucionalismo español, op. cit., pp. $73-74$.

33 José Maria Portillo Valdés, “De la Monarquía Católica a la Nación de los Católicos”, Historia y Política, $\mathrm{n}^{\circ}$ 17, 2007, p. 19. Las palabras de Joaquín $\mathrm{M}^{\mathrm{a}}$ López en Diario de Sesiones de Cortes Constituyentes (DSCC en adelante), n 161, 6 de abril de 1837, p. 2521.

34 Agustín De Argüelles, Exámen histórico de la reforma constitucional que hicieron las Córtes Generales y Estraordinarias desde que se instalaron en la Isla de León el día 24 de setiembre de 1810, hasta que cerraron en Cádiz sus sesiones en 14 del propio mes de 1813, Londres, Carlos Wood e hijo, 1835, pp. 71-72. 
por sus intereses. Por ello, se pospuso la decisión de avanzar hacia una tolerancia religiosa verdadera.

El recuerdo de lo aprobado en Cádiz y el deseo de no repetir los errores hicieron que los debates al respecto fueran enconados, con propuestas como la del progresista Joaquín María López, que abogaba por prohibir toda persecución religiosa "siempre que se respete el culto establecido, la moral y las leyes que lo protegen", aunque no admitía la libertad de cultos públicos en España ${ }^{35}$ por los problemas de orden que acarrearía. Landero, secretario del despacho de Gracia y Justicia, y Sarabia se pronunciaron en un sentido similar defendiendo que ningún español pudiera ser molestado por opiniones religiosas, pero los miembros de la Comisión Constitucional con Argüelles a la cabeza, aunque aplaudieron el espíritu de tolerancia, defendieron que este desarrollo legislativo se hiciera fuera del texto constitucional:

\begin{abstract}
"Las leyes que quieren establecer la tolerancia, producen lo opuesto, provocan las contiendas, irritan los ánimos, excitan las disputas. No es eso, sino la prudente circunspección, lo que deja la materia intacta y la cuestión en su verdadero estado, para que las Cortes sucesivas hagan lo que deban hacer. Pues que ¿no sería de parte nuestra presunción imperdonable creer que las Cortes sucesivas serán menos ilustradas, menos patriotas que éstas?"36
\end{abstract}

Por contraste con la mayoria favorable a avances en derechos y libertades, hubo intervenciones opuestas extremas. Desde las posiciones más conservadoras se pedía subrayar el sentido religioso y restaurar el carácter especial que tenía la religión en 1812. Destacaron también aquellos liberales que, como Fermín Caballero, no veían necesario tratar el tema de la religión en el texto constitucional, ${ }^{37}$ para no mezclar cuestiones politicas y religiosas.

No ocurriría lo mismo con la libertad de cultos: se rechazó unánimemente que la práctica religiosa diese el salto del fuero interno a la visibilidad y organización públicas. La única excepción entre los diputados fue Martín de los Heros, que alertó sobre la contradicción que suponía no permitirla. Defendía que la plasmación pública más auténtica de la libertad de conciencia no podía ser otra que la libertad de cultos. ${ }^{38} \mathrm{En}$ su contra se aducian los males sociales que podrian surgir si era aprobada, contraponiéndolos a las ventajas de orden público que concedia la unidad religiosa pública. Landero aprovecha su palabra en sede parlamentaria para negar, por dos veces, que él desee una libertad indefinida, esto es, la ley de cultos. ${ }^{39}$

35 DSCC, no 142,14 de marzo de 1837 , p. 2136.

36 DSCC, $\mathrm{n}^{\circ} 159,4$ de abril de 1837, pp. 2478 y 2483.

37 Antonio Colomer Viadel, El sistema politico de la Constitución española de 1837, Madrid, Publicaciones del Congreso de los Diputados, 1989, p. 106.

38 Abraham Barrero Ortega, Modelos de relación entre el Estado y la Iglesia en la historia constitucional española, Cádiz, Servicio de Publicaciones de la Universidad de Cádiz, 2007, pp. 2831 .

39 DSCC, $n^{\circ} 159,4$ de abril de 1837 , pp. 2479-2480. 
Salustiano de Olózaga, tras reconocer su apoyo a la libertad de cultos en el pasado, en ese momento, tras viajar por Europa, se opuso a ella, pues "[vio] que uno de los mayores males que les aflige [a los demás países] es la libertad de creencias y me felicité y me felicito porque en España tengamos esta unidad de opiniones, que desearía que no se perdiera jamás”. Y ahondó en la importancia de la unidad religiosa como factor de orden público y del cumplimiento de la ley que lo garantiza:

\begin{abstract}
"si importa tanto para que formemos un todo compacto, para que seamos verdaderamente libres que nos uniformemos en las materias más esenciales de moral y de gobierno; ¿cómo no ha de importar que tengamos esta uniformidad misma en lo que se hace sentir a todas horas, en todas las ocasiones de la vida y en todas las clases de la sociedad? No hay hombre, señores, (...), que no se halle en la necesidad de tener una creencia conforme con la de los demás, ó que él tenga el valor ó capricho de formarse. (...)
\end{abstract}

La desunión se aumenta, la armonía se pierde, cuando el uno cree que el padre se salva por los consuelos de la religión que ha invocado, otro hijo de diferente creencia siente más la perdición eterna de su padre que su pérdida temporal. (...)

Señores, el ser regidos por una autoridad, el vivir con unas mismas costumbres, el tener unos mismos intereses, forman y deben formar la felicidad de los hombres. Si á esto se añade la unidad de sentimientos, (...) ¿cómo podrá vivirse en ellos de esta manera, formar un todo homogéneo, cuando sus habitantes vayan á diferentes templos y tengan diferentes religiones? (...)

¿No sería un mal inmenso el que aumentásemos á esos motivos de división uno más fuerte, que la historia nos presenta con toda claridad, como es la diversidad de religiones? ¿Qué sería de nosotros en la actualidad misma, si defensores unos nada más que del absolutismo y de ciertos principios, lo fueran al mismo tiempo de opiniones religiosas? ¿Qué esperanza podriamos tener de concluir pacíficamente esta guerra cuando nuestras armas victoriosas aniquilen las fuerzas del absolutismo? ¿No podriamos creer que jamás se extinguiria la lucha que deseamos y que esperamos ver terminada? Mezclemos, señores, principios religiosos á la división política en que nos hallamos, y ipobre España entonces!" 40

Desde ciertos sectores se pensaba que cualquier ruptura en la cohesión religiosa implicaría la pérdida de la armonía social y política con que contaba España. No podía renunciarse al armazón que la unidad de fe suponía para el mantenimiento del orden social. Entregarlo además al enemigo carlista constituiria un error garrafal y la guerra ("esa lucha que deseamos y que esperamos ver terminada") podía darse por perdida si eso ocurría.

En ese sentido se expresaría Joaquín María López, Secretario del Despacho de Gobernación de la Península, quien, partiendo de la defensa de la necesidad de la religión para todo gobierno, afirmaba que se requiere además una "fuerza activa que siga al hombre en todas partes, que lo acompañe en la soledad y que penetrando en su interior, erija allí un juez inexcusable". Con la religión presente

40 DSCC, $\mathrm{n}^{\circ} 161,6$ de abril de 1837 , pp. 2524-2526. 
a la vez en el foro interno y la vida pública, "la voz de la conciencia se mezcla con la de la ley, el cumplimiento de los deberes sociales forma parte de las obligaciones religiosas, y uniéndose un vínculo a otro, su efecto es más inmediato y más poderoso". ${ }^{41}$ Aunque no mencionaba la unidad religiosa, sí afirmaba que la presencia de una serie de principios y creencias compartidas fomentaba el cumplimiento de las obligaciones legales y sociales; esto es, la religión daba estabilidad y apoyaba el mantenimiento del orden a través de la obediencia a las normas, dictada desde la propia conciencia.

En el mismo debate, aunque Olózaga, que ya destacó el poder de la unidad religiosa para lograr el establecimiento del orden público, reconoció la posibilidad de una diversidad de cultos en la sociedad, al mismo tiempo no percibía la necesidad de legislar de esa forma en España, a causa de la Inquisición, para después mostrarse aliviado por la ausencia de "sectas diferentes":

\begin{abstract}
"cuando una Nación por la agregación de otras, por el nacimiento de ciertas sectas, por efecto de circunstancias particulares, ha perdido la unidad de su creencia, (...) que cuando un pueblo se ve dividido de esta manera, y cuando los individuos de un Estado tienen diferentes ideas sobre este particular, las leyes, en nombre de la razón, deben dispensar la tolerancia y la protección en favor de los individuos disidentes" (...)

"los españoles no han perdido su unidad de fe y de creencia. Y cuando tenemos este vínculo de unión, que es tanto más fuerte cuanto abraza ó alcanza á todas las clases, á todos los estados; cuando nos une á todos un vínculo moral por el que nos miramos como hermanos, (...) ¿Qué objeto podrá tener una ley de libertad religiosa, de que nadie quiere ni tiene necesidad de usar?"42
\end{abstract}

Por su parte, Esquivel, diputado por Córdoba, opinando en contra de la inclusión de la tolerancia religiosa en la Constitución, advirtió de los riesgos desestabilizadores de ésta si se llevase a la escena pública: "si se trata de la manifestación del pensamiento, ¿quién es el que podrá asegurar que la manifestación de los pensamientos, tanto políticos como religiosos, no puede trastornar un Estado? Yo me alegraré que lleguemos á esa época en que los ciudadanos prescinden de materias de opinión y les sea indiferente que cada uno opine según su convencimiento; pero aún no nos hallamos en este caso."43 La sociedad no estaba preparada para reaccionar de forma pacífica a la expresión en público de opiniones religiosas diferentes a la católica; los desórdenes eran más que previsibles.

El secretario Landero rescató la relación entre orden y religión, cuando afirmó que la católica es "la más propia para mantener el orden y la tranquilidad pública, para conservar la unión en los pueblos y hacer la felicidad en la sociedad. (...) asegura del modo más positivo la paz y el sosiego de la sociedad". ${ }^{44}$

\footnotetext{
${ }^{41}$ DSCC, $\mathrm{n}^{\circ} 142,14$ de marzo de 1837, p. 2136.

42 Ibid, p. 2139.

43 DSCC, $\mathrm{n}^{\circ} 161,6$ de abril de 1837, p. 2517.

44 DSCC, $n^{\circ} 159,4$ de abril de 1837, p. 2478.
} 
Aunque se presentaron numerosas enmiendas, se aprobó el artículo por 125 votos a favor frente a 34 en contra. Estos debates sobre la cuestión religiosa fijarian las posturas liberales a lo largo del constitucionalismo del XIX. Dos días después, un editorial del diario El Español, dirigido por Donoso Cortés, reflexionaba sobre la cuestión y concluía que

En la religión está todo fundamento de orden, todo principio de moralidad, toda sanción de gobierno; sin ella, la sociedad reposa toda entera sobre el cadalso. (...)

La sociedad no puede existir sino sobre ideas; y entre todas las ideas, ningunas tienen tanto poder, ningunas merecen con tanta verdad ese nombre como las ideas religiosas. (...) La humanidad no se conmueve con la razón, se conmueve solo con la fe. 45

Como puede verse, la identificación entre orden público y religión compartida fue constante a lo largo de los debates, y se relacionaba con la eterna discusión sobre si debía prevalecer el orden o si por el contrario debía hacerlo la libertad, en el ámbito que fuera.

\section{4.-Elementos económicos y de control sobre la Iglesia en el artículo 11}

Todas estas disquisiciones eran compatibles con el reciente proceso de desamortización eclesiástica y con otros decretos, como el aprobado el 8 de marzo de 1836, que suponía la supresión de todos los monasterios y conventos de varones. ${ }^{46}$ Vinculada a estos fenómenos, la redacción del artículo 11 era, especialmente en la obligación al mantenimiento del culto y del clero, una contrapartida financiera a dicha desamortización. Suponía en realidad una "confesionalidad presupuestaria o tutelar" del Estado, ${ }^{47}$ que se situaba en una posición de apoyo a la subsistencia de Iglesia, al tiempo que limitaba parcialmente la posible influencia del clero.

Se trataba de una compensación constitucional a los perjuicios de los años precedentes, nivelando las tradicionales fuentes de ingresos de las que habian despojado al clero. Se vería desarrollada por la Ley de 29 de julio de 1837, que, poco después de la aprobación de la Constitución, creaba la contribución de culto y clero. ${ }^{48}$ Con este cambio de actitud, se intentaba mitigar la ruptura de las relaciones con la Santa Sede, ocurrida tras la llegada al poder de Calatrava.

45 El Español, 8 de abril de 1837, pp. 2-3.

46 Ricardo García García, Constitucionalismo español y legislación sobre el factor religioso durante la primera mitad del siglo XIX (1808-1845), op. cit., pp. 10 y 338. También Jerónimo Bécker, Relaciones diplomáticas entre España y la Santa Sede en el siglo XIX, op. cit., p. 108.

47 José Agustín González-Ares, Las Constituciones de la España contemporánea. Del Estatuto de Bayona a las Leyes Fundamentales del franquismo. Santiago de Compostela, Andavira Editora, 2010, p. 58.

48 Abraham Barrero Ortega, Modelos de relación entre el Estado y la Iglesia en la historia constitucional española, op. cit., pp. 24-25. 
Sin embargo, aparte de las causas económicas, hubo también motivos políticos en el reconocimiento específico del credo católico en el articulado. No podía abandonarse la bandera de la religión católica, poniéndosela en bandeja de los carlistas, cuya derrota estaba aún lejana. El pueblo español seguía unido a ella, y perder ese baluarte de legitimidad podria haber resultado fatal para las aspiraciones de consolidación del Estado liberal ante un clero dividido entre los partidarios de ambos bandos. La politica de estricta neutralidad en el conflicto que desarrolló el Papado generó muchos temores entre los isabelinos. La Santa Sede mantuvo esta posición durante largo tiempo, y de hecho el reconocimiento de la hija de Fernando VII como reina de España no llegaría hasta 1855.

También era importante el control politico directo sobre las estructuras eclesiásticas. Existía la tentación (y la intención) de formar un nuevo regalismo de corte liberal, que fuese una evolución del tradicional regalismo español, en el que los miembros del clero, bajo control gubernamental, se conviertan en funcionarios del Estado, dado que su sueldo procedía de las arcas públicas, y, en consecuencia, en instrumentos de la politica liberal. ${ }^{49}$ Puede entenderse este proceso dentro otro de mayor envergadura destinado a incrementar y fortalecer las atribuciones estatales en España.

\section{5.-Promulgación religiosa y años posteriores}

El Gobierno deseaba que la promulgación de la nueva Constitución llegase a todos los rincones del país, por lo que publicó un decreto que indicaba que era necesaria una solemne ceremonia de promulgación en "el paraje acostumbrado" de reunión de la población, donde se leería al completo y se proclamaría su obligatoriedad.

Pero este acto cívico no sería el único. Ese mismo Decreto recogía que la promulgación de la Constitución fuese acompañada o seguida de actos religiosos para llegar más fácilmente a las conciencias. En el primer día festivo tras la promulgación "se celebrará una misa solemne de acción de gracias; se leerá la Constitución antes del ofertorio; se hará por el cura párroco o por el que éste designe una breve exhortación correspondiente al objeto; después de concluida la misa, se prestará juramento por todos los vecinos y el clero, a una voz y sin preferencia, de guardar la Constitución...". A continuación, tendría lugar un Te Deum.

La combinación de ambos actos, cívico-político y religioso, pretendía acercar la Constitución lo máximo posible a los ciudadanos, implicándolos de esa forma en el proceso. El cumplimiento del decreto fue desigual según los municipios. La presencia de la guerra carlista impidió que donde habia enfrentamientos tuviesen lugar celebraciones de esta clase. Asimismo, autores como Alcalá Galiano afirman que el entusiasmo apenas salía de Madrid capital, donde sí se dieron los actos correspondientes, pero no en el medio rural u otras ciudades. 50 Todas estas medidas, junto al propio carácter del texto legal, desmienten la denominación de

\footnotetext{
49 Antonio Colomer Viadel, El sistema politico de la Constitución española de 1837, op. cit., p. 119.

50 Joaquín Tomás Villaroya, “La publicación de la Constitución de 1837”, op. cit., p. 22.
} 
"ciudadanía laica" que según autores como Pro Ruiz ${ }^{51}$ implica la Constitución de 1837.

Para incrementar el control sobre la Iglesia, durante la Regencia de Espartero se intentó la creación de una "iglesia nacional" a través de un proyecto de ley presentado en 1842,52 que finalmente no fue aprobado por falta de acuerdo incluso entre los progresistas. Buscaba la reducción de las tensiones con Roma cortándolas de raíz a través de medidas económicas, pero eliminando en la medida de lo posible la influencia de la Santa Sede sobre los prelados españoles, al separar espiritualmente ambas instituciones. Se trata de una actuación impregnada de dualismo.

La presencia de la religión en la vida pública fue constante. De hecho, escribir la historia de la España del siglo XIX fue, como dijo Galdós "el secreto de introducir el alma de Pío IX en el cuerpo de Espartero". ${ }^{53}$

\section{IV.-CONCLUSIONES}

Durante los dos primeros tercios del siglo XIX, la politica española tuvo serias dificultades para combinar vocación liberal y tolerancia religiosa. Quizá el motivo se halle en la percepción, extendida sobre todo en parte de los sectores conservadores, de la inseparabilidad entre el ser de España y la Iglesia, a la que se pertenecía prácticamente por el hecho de ser español. No obstante, si bien para muchos la equivalencia entre españolidad y catolicismo era completa, el reconocimiento de la libertad de cultos en la Constitución de 1869 dejó patente que las posturas en torno a esta cuestión eran diversas.

Las ideas políticas de los liberales fueron imponiéndose, aunque lentamente, siempre dentro de los márgenes económicos y sociales existentes. Cuando se trataba de cuestiones religiosas, el liberalismo español fue más inflexible por norma hasta muy avanzado el siglo. Los puntos de vista sobre los lazos que unen religión y orden pueden agruparse en dos categorias. Por un lado, se encuentra la garantía del mantenimiento del respeto a la ley cuando se mantenga la unidad de fe, y por otro, está la predicción de futuras querellas y nuevos problemas sociales en caso de que la unidad religiosa desapareciese.

Cualquier avance a favor de la libertad religiosa se realizó con máxima cautela, empleando en todo momento fórmulas ambiguas no demasiado rupturistas, pues toda iniciativa encaminada a liberar de la tutela eclesiástica a los españoles fue automáticamente interpretada por la Iglesia como un ataque frontal, cuyas consecuencias repercutirian en el conjunto del país, inconcebible sin unidad religiosa. Se anticipaban efectos espeluznantes de todo tipo si se agrietaba la monolítica unidad de credo de los españoles. Una pequeña fractura podía terminar con todo el edificio.

51 Juan Pro Ruiz, El Estatuto Real y la Constitución de 1837. Madrid, Iustel, 2010, p. 114.

52 Gregorio Alonso García, La nación en capilla: ciudadanía católica y cuestión religiosa en España, 1793-1874, op. cit., pp. 176-180.

53 Benoît Pellîstrandi, "Catolicismo e identidad nacional en España en el siglo XIX", en Paul Aubert, Religión y sociedad en España: (siglos XIX y XX): seminario celebrado en la Casa de Velázquez (1994-1995), op. cit., p. 120. 
Dentro y fuera de la jerarquía católica, se consideraba que la unidad de fe no podía ni debía ser destruida de cara a evitar el descontrol en la paz pública, además de problemas en el cumplimiento de la legalidad. Existía un consenso importante sobre la presencia de numerosos problemas en España, pero ese acuerdo generalizado incluía también la idea de que la ausencia de "sectas" alternativas a la católica había evitado muchas otras dificultades de orden que sí estaban presentes en otros países. La tolerancia religiosa podía ser vista como una opción "contaminadora", como el primer paso hacia un serio resquebrajamiento de la fe y, por tanto, hacia el desorden.

El protagonismo del hecho religioso en la política y los debates constituyentes apareció con especial intensidad durante la discusión en Cádiz sobre la abolición de la Inquisición (1812-1813), que incluyó análisis y disquisiciones sobre el origen y la evolución de dicha institución.

El impacto de la oportunidad y el contexto políticos fue verdadero: los liberales de 1812 tuvieron que ceder ante las pretensiones de la Iglesia, incapaces de hacerles frente, como reconocería Argüelles años después. Conscientes del alcance de las otras reformas ya incluidas en el texto constitucional, entre los parlamentarios existía cierto temor a ir demasiado lejos con los cambios. Los frentes abiertos ya eran numerosos y la perspectiva de crear otros nuevos no era precisamente atrayente. Por su parte, en 1837, en mitad de la guerra, los constituyentes eran conscientes de la seria inconveniencia que supondria entregar a los carlistas el monopolio de la defensa de la religión. Los motivos para esgrimir la unión de fe como arma de cohesión y tranquilidad política y social podian cambiar, pero permanecian presentes.

Confesionalidad presupuestaria, confesionalidad sociológica o incluso ciudadanía laica son algunos de los calificativos que la historiografia ha asignado a la forma en que las Cortes Constituyentes de 1837 afrontaron la cuestión religiosa, frente a la confesionalidad total de 1812. La posición elegida en ese momento muestra la dificultad para delimitar el nuevo sistema, mejor definido como una combinación de las confesionalidades presupuestaria y sociológica, junto a una "aconfesionalidad nacional-institucional". La primera parte del artículo constitucional sobre religión es puramente económica, frente al carácter sociológico de la segunda. El comienzo solamente enuncia la única obligación que recoge el artículo: reservar parte del presupuesto público al sostenimiento del clero y otros gastos relacionados con el culto católico. Desaparecía así la vinculación legal entre españolidad y catolicismo: el final del artículo constata un estado sociológico de cosas: el catolicismo profesado por (todos) los españoles, eso sí, entendidos como individuos; la nación ya no es un ente con religión propia, frente a lo reflejado en 1812, donde además se explicitaba un elemento valorativo. El cambio en el "sujeto con credo" es significativo: la nación española deja paso a los españoles.

El siglo XIX pivotó sobre dos ideas-fuerza: libertad y orden, situadas en una balanza incapaz de equilibrarse, en una dicotomía sin duda influida por la sombra ejercida por la Revolución Francesa. La preferencia por el predominio de una $u$ otra en la acción política marcaba la pertenencia al partido moderado o al progresista. Este debate también alcanzó la cuestión religiosa, pero sin avances significativos. Gradualmente, distintas libertades (de imprenta, de asociación...) fueron creciendo y desarrollándose. Sin embargo, no ocurrió lo mismo con la libertad de fe, cuya evolución quedó varada durante años, hasta 1869, en pos del 
mantenimiento del orden. Sólo entonces se estableció por completo la libertad de cultos, esto es, la libre profesión pública y privada de los credos.

Mientras tanto, durante las décadas centrales del siglo, la libertad religiosa se mantuvo de forma continua en cada uno de los numerosos debates constitucionales como la última frontera que nadie se atrevía a cruzar alegando, desde posturas ideológicas dispares, el deseo de conservar el orden público, ya fuera por propia convicción, por presiones directas de la jerarquía católica o por el deseo de no entregar a los absolutistas un arma extra a la hora de recibir apoyos en la contienda carlista.

Se veía a la unidad religiosa como el anclaje final antes de que la anarquía llegase, el último lazo que cohesionaba una sociedad social, política y económicamente fragmentada. $\mathrm{Ni}$ una invasión francesa ni las ansias renovadoras de los primeros años de Regencia de María Cristina fueron capaces de acabar con ella. Harian falta tres décadas y un destronamiento para superar todo temor al respecto y para que las libertades religiosa y de cultos llegasen a buen puerto con políticos que al fin y al cabo también eran católicos.

Fecha de envio / Submission Date: 24-06-2015

Fecha de aceptación / Acceptance Date: 15-09-2015 